ARTIGO

\title{
Modalidades de ensino nas universidades brasileiras e portuguesas: um estudo de caso sobre a percepção de alunos e professores em tempos de Covid-19
}

\author{
Amanda Maraschin Bruscato' \\ Jorge Baptistal
}

\section{RESUMO}

Este artigo apresenta uma análise da utilização de diferentes modalidades de ensino no ensino superior, considerando o contexto atual provocado pela COVID-19. O estudo baseia-se em uma revisão da literatura sobre o tema e questionário aplicado a 225 estudantes e professores universitários do Brasil e de Portugal, dos quais 144 tiveram suas aulas presenciais substituídas por aulas a distância. A maioria dos respondentes considera o ensino a distância pior do que o presencial, a comunicação pior, a avaliação mais difícil, a exigência maior e a aprendizagem pior. Além disso, os professores julgam empregar muito mais de seu tempo e dedicação para o ensino a distância, enquanto os alunos parecem dedicar-se menos. Ao serem questionados sobre o futuro do ensino superior, a maioria acredita que a modalidade de ensino mais utilizada será a híbrida. Apesar de o ensino a distância proporcionar diversas vantagens, os participantes sentem falta da interação face a face.

PALAVRAS-CHAVE

COVID-19; ensino superior; modalidades de ensino.

'Universidade do Algarve, Faro, Portugal. 


\title{
TEACHING MODALITIES IN BRAZILIAN AND PORTUGUESE UNIVERSITIES: A CASE STUDY ON THE PERCEPTION OF STUDENTS AND PROFESSORS IN TIMES OF COVID-19
}

\begin{abstract}
This article presents an analysis of the use of different teaching modalities in higher education, considering the current context provoked by COVID-19. The study is based on a literature review on the subject and on a questionnaire applied to 225 university students and professors from Brazil and Portugal, of which 144 had their face-to-face classes replaced by distance classes. Most respondents consider distance learning worse than face-to-face, the communication worse, the assessment more difficult, the demand higher, and the learning worse. In addition, professors think they spend much more of their time and dedication for distance learning, while students seem to engage less. When asked about the future of higher education, most believe that the most used teaching modality will be the hybrid one. Although distance learning provides several advantages, participants miss face-to-face interaction.

KEYWORDS

COVID-19; higher education; teaching modalities.

\section{MODALIDADES DE ENSEÑANZA EN UNIVERSIDADES BRASILEÑAS Y PORTUGUESAS: UN ESTUDIO DE CASO SOBRE LA PERCEPCIÓN DE ESTUDIANTES Y PROFESORES EN TIEMPOS DE COVID-19}

\section{RESUMEN}

Este artículo presenta un análisis del uso de diferentes modalidades de enseñanza en la educación superior, considerando el contexto actual ocasionado por la COVID-19. El estudio se basa en una revisión de la literatura sobre el tema y en un cuestionario aplicado a 225 estudiantes y profesores universitarios de Brasil y Portugal, de los cuales 144 tuvieron sus clases presenciales reemplazadas por clases a distancia. La mayoría de los participantes consideran que el aprendizaje a distancia es peor que el presencial, que la comunicación es peor, la evaluación más difícil, la exigencia mayor y el aprendizaje peor. Además, los docentes dedican mucho más tiempo y dedicación al aprendizaje a distancia, mientras que los estudiantes parecen dedicarse menos. Al preguntarles sobre el futuro de la educación superior, la mayoría cree que la modalidad de enseñanza más utilizada será la modalidad híbrida. Aunque el aprendizaje a distancia ofrece varias ventajas, los participantes extrañan la interacción cara a cara.

COVID-19; enseñanza superior; modalidades de enseñanza. 


\section{INTRODUÇÃO}

Este artigo tem como objetivo refletir sobre a percepção de estudantes e professores quanto à utilização de diferentes modalidades de ensino no ensino superior, considerando o contexto atual de pandemia provocado pela COVID-19. Inicialmente, será apresentada uma revisão da literatura sobre as modalidades de ensino, em especial referentes ao ensino de línguas. $\mathrm{Na}$ sequência, será descrito um questionário aplicado a estudantes e professores universitários do Brasil e de Portugal, em que se pretende compreender como o ensino a distância é percebido no meio acadêmico.

De acordo com a Organização Mundial da Saúde ${ }^{1}$, a COVID-19 (Coronavirus Disease 2019) é uma doença respiratória provocada por um vírus descoberto na China no fim de 2019. Rapidamente, o vírus se espalhou pelo mundo, infectando milhões de pessoas e levando centenas de milhares a óbito. Em virtude do alto grau de contágio e letalidade do vírus, à falta de vacina e medicação, bem como ao número insuficiente de testes, de leitos de emergência e de aparelhos respiratórios disponíveis, diversos países decidiram aplicar medidas de distanciamento social.

Em obediência a essa determinação, as instituições de ensino foram temporariamente fechadas, bem como estabelecimentos de serviços não essenciais. As pessoas foram instruídas a evitar ao máximo sair de suas residências, limitando-se, por exemplo, às idas ao supermercado e, em casos de emergência, a farmácias e hospitais.

$\mathrm{Na}$ China, a quarentena foi imposta a partir de 3 de fevereiro de 2020, quando o país já contava com mais de 20.400 casos confirmados e 425 mortes pela doença. $\mathrm{Na}$ Itália, a medida teve início a partir de 9 de março, quando havia mais de 9 mil casos confirmados e 463 mortes. Na Espanha, a partir de 14 de março, quando havia mais de 5.700 casos confirmados e 136 mortes $^{2}$. Em Portugal, a restrição à circulação entre pessoas foi anunciada no dia 19 de março, quando havia 642 casos confirmados e 2 mortes ${ }^{3}$. No Brasil, sem o apoio do presidente da República, alguns estados iniciaram o distanciamento social a partir de 16 de março, quando havia 234 casos confirmados e 1 morte 4 .

Enquanto algumas instituições de ensino suspenderam completamente as atividades acadêmicas (caso de diversas universidades públicas brasileiras), outras substituíram as atividades presenciais por atividades a distância (caso de diversas

1 Disponível em: https://www.who.int/emergencies/diseases/novel-coronavirus-2019. Acesso em: 8 maio 2020.

2 Disponível em: https://gauchazh.clicrbs.com.br/saude/noticia/2020/03/veja-as-medidas-dos-paises-que-conseguiram-conter-o-coronavirus-ck80lgsaq06gf01pqhx9gbw 94. html. Acesso em: 8 maio 2020.

3 Disponível em: https://g1.globo.com/mundo/noticia/2020/03/19/portugal-declara-estado-de-emergencia-por-causa-do-coronavirus.ghtml. Acesso em: 8 maio 2020.

4 Disponível em: https://g1.globo.com/bemestar/coronavirus/noticia/2020/04/16/50-dias-do-novo-coronavirus-compare-a-situacao-do-brasil-com-china-italia-eua-e-outros-paises-no-mesmo-periodo-da-epidemia.ghtml. Acesso em: 8 maio 2020. 
universidades privadas brasileiras e portuguesas). Nesse contexto, as universidades privadas decidiram oferecer aulas a distância como meio de garantir o pagamento das mensalidades e manter o quadro de funcionários; já as universidades públicas que suspenderam as aulas argumentam que as desigualdades econômicas e sociais no Brasil impedem que todos os estudantes tenham igual acesso ao ensino a distância ${ }^{5}$.

Além de ressaltar as disparidades existentes na sociedade brasileira, o distanciamento social pode impactar negativamente na saúde mental dos envolvidos ${ }^{6}$. Para esse entendimento, é preciso ter em conta que algumas pessoas moram sozinhas, outras, por sua vez, vivem com um número excessivo de pessoas, e há ainda quem viva com famílias abusivas, fatores que podem efetivamente abalar o emocional, ainda mais pela necessidade de se trabalhar ou estudar remotamente, o que exige adaptações. Considerando que a economia é diretamente afetada pela pandemia, com medidas restritivas de circulação e abertura de comércios, muitos também se preocupam com a situação que será enfrentada durante e após esse período. É preciso considerar diversas variáveis, portanto, antes de decidir ou não pelo ensino a distância.

De modo que se possa compreender melhor como o ensino a distância é percebido atualmente por estudantes e professores universitários no Brasil e em Portugal, procedeu-se a um estudo baseado em um questionário divulgado online durante a última semana de abril de 2020, a que responderam 225 pessoas, cuja análise é o objetivo principal deste artigo. Antes, porém, será apresentada uma revisão da literatura sobre as modalidades de ensino presencial, híbrida e a distância.

\section{REVISÃO SOBRE MODALIDADES DE ENSINO}

Em razão dos avanços tecnológicos das últimas décadas, que têm modificado as relações humanas nos diferentes níveis, era esperado que a demanda pelo ensino a distância aumentasse. De acordo com a Organização para a Cooperação e Desenvolvimento Econômico (OECD, 2019), a porcentagem de portugueses entre 25 e 34 anos formados no ensino superior passou de $11,5 \%$ para $23,2 \%$ e $35,1 \%$, respectivamente nos anos de 1998, 2008 e $2018^{7}$. Já a porcentagem de estudantes internacionais matriculados em universidades portuguesas aumentou de 2,876\%, em 2010, para 6,397\%, em $2017^{8}$. De acordo com Teixeira (2017), o custo e a procura crescente pelo ensino superior, a facilidade das tecnologias e a migração humana incentivam a oferta do ensino a distância. Apesar de a necessidade dessa modali-

5 Disponível em: https:/g1.globo.com/educacao/noticia/2020/03/27/universidades-publicas-suspendem-aulas-virtuais-em-meio-ao-coronavirus-particulares-se-mobilizam-contra-reducao-de-mensalidades.ghtml. Acesso em: 8 maio 2020.

6 Disponível em: http://www.ms.gov.br/coronavirus-saude-mental-tambem-precisa-de-atencao-e-cuidados/. Acesso em: 8 maio 2020.

7 Disponível em: https://data.oecd.org/eduatt/population-with-tertiary-education.htm. Acesso em: 8 maio 2020.

8 Disponível em: https://data.oecd.org/students/international-student-mobility.htm. Acesso em: 8 maio 2020. 
dade de ensino ter aumentado nos últimos anos, em 2020 assistiu-se à sua rápida expansão pelo mundo em virtude do contexto de pandemia. Importante mencionar que uma das preocupações que emergem desse modo de ensinar, também destacada por Teixeira (2017), é que a falta de contato presencial prejudicaria a aprendizagem, e por isso o ensino híbrido - parte a distância e parte presencial - possa ser a melhor alternativa.

Considerando essas observações, nesta revisão serão apresentadas algumas modalidades de ensino possíveis, além de algumas teorias de ensino-aprendizagem. Serão discutidas três modalidades: a modalidade presencial; a modalidade a distância, também conhecida como e-learning; e a modalidade híbrida, também conhecida como b-learning. Na sequência, serão analisados os resultados de um questionário realizado com alunos e professores do ensino superior do Brasil e de Portugal.

A modalidade de ensino presencial é a mais antiga de todas, pois, para que ela possa ocorrer, é imprescindível apenas que alguém disposto a ensinar esteja no mesmo ambiente que alguém disposto a aprender. Apesar da distinção estabelecida entre professor e aluno, a função que cada um desempenha no processo de ensino-aprendizagem pode variar dependendo do modelo pedagógico adotado. No questionário, foi elaborada uma questão sobre como os participantes do processo de ensino-aprendizagem percebem a interação pedagógica em suas aulas.

De acordo com Becker (1994), o modelo pedagógico que orienta o ensino-aprendizagem pode ser diretivo, não diretivo ou relacional. $O$ autor explica que a pedagogia diretiva fundamenta-se na epistemologia empirista. Segundo essa epistemologia, "o sujeito é totalmente determinado pelo mundo do objeto ou meio físico e social", e o modelo pedagógico nela baseado, portanto, considera que "o professor ensina e o aluno aprende" (Becker, 1994,p. 90). A pedagogia não diretiva, por sua vez, fundamenta-se na epistemologia apriorista, que defende a ideia de que "o ser humano nasce com o conhecimento já programado na sua herança genética”, e o modelo pedagógico nela baseado, portanto, considera que "o professor deve interferir o mínimo possível" (Becker, 1994,p. 91).Já a pedagogia relacional fundamenta-se na epistemologia construtivista. Para essa epistemologia, a aprendizagem "é síntese do que existia, antes, como sujeito - originalmente, da bagagem hereditária - e do conteúdo que é assimilado do meio social", e o modelo pedagógico nela baseado, portanto, considera que "o professor, além de ensinar, precisa aprender o que seu aluno já construiu até o momento" (Becker, 1994, p. 93).

$\mathrm{O}$ ensino-aprendizagem não precisa ocorrer apenas conforme um modelo pedagógico. $\mathrm{O}$ professor pode, por exemplo, iniciar a aula com uma atividade de reflexão sem fazer interferência, utilizando a pedagogia apriorista, de modo que os estudantes mobilizem seus conhecimentos prévios sobre o assunto. Depois, pode pedir que a turma discuta suas conclusões e pode orientá-la, utilizando assim a pedagogia relacional para entender o que os alunos sabem e ensinar o que não sabem. Por fim, pode realizar uma exposição sobre o assunto, utilizando a pedagogia empirista para explicar o que os estudantes não sabiam. Será visto, posteriormente, se os respondentes identificam a combinação dos modelos pedagógicos em suas aulas ou percebem algum como dominante.

Os tipos de relação estabelecidos entre o sujeito/aluno (S/A) e o objeto/ professor (O/P) foram organizados por Becker (1994), conforme Quadro 1: 
Quadro 1 - Comparação dos modelos pedagógicos e epistemológicos.

\begin{tabular}{|c|c|c|c|}
\hline \multicolumn{2}{|c|}{ EPISTEMOLOGIA } & \multicolumn{2}{c|}{ PEDAGOGIA } \\
\hline Teoria & Modelo & Modelo & Teoria \\
\hline Empirismo & $\mathrm{S} \leftarrow \mathrm{O}$ & $\mathrm{A} \leftarrow \mathrm{P}$ & Diretiva \\
Apriorismo & $\mathrm{S} \rightarrow \mathrm{O}$ & $\mathrm{A} \rightarrow \mathrm{P}$ & Não Diretiva \\
Construtivismo & $\mathrm{S} \leftrightarrow \mathrm{O}$ & $\mathrm{A} \leftrightarrow \mathrm{P}$ & Relacional \\
\hline
\end{tabular}

Fonte: baseado em Becker (1994, p. 94).

Pode-se identificar, para cada modelo pedagógico, pelo menos uma abordagem de ensino. De acordo com Brown (2007, p. 48), o século XX foi marcado pela busca de uma abordagem e de um método de ensino melhores que os então utilizados. No ensino de línguas, relacionada à teoria empirista surgiu a abordagem áudio-oral (Bloomfield, 1942); relacionada à teoria apriorista surgiu a abordagem natural (Terrell, 1977); e relacionada à teoria construtivista surgiu a abordagem comunicativa (Wilkins, 1973), como se viu em Cunha e Bruscato (2019) e Bruscato e Baptista (2020).

As abordagens de ensino de línguas costumam considerar tanto as teorias de aprendizagem como as teorias linguísticas e podem ser praticadas de acordo com distintos métodos de ensino. Independentemente da modalidade de ensino adotada, o professor aplica um ou mais métodos que considera adequados ao seu grupo de estudantes. De acordo com Anthony (1963, p. 63-67), em uma hierarquia, técnicas executam um método consistente com uma abordagem. Enquanto a abordagem surge das suposições que o professor tem sobre o ensino-aprendizagem de línguas, o método é o plano de procedimentos baseado na abordagem, e a técnica é cada estratégia utilizada para implementá-lo em aula. Desse modo, tem-se que os métodos são a aplicação da abordagem teórica adotada pelo professor.

Nessa direção, a crença de que o professor precisa adotar apenas um método ou uma abordagem era comum no século passado, mas atualmente já é evidente que não há uma abordagem nem um método melhor que outro para todas as situações. Concorda-se com Prabhu (1990), que cada professor deva considerar suas preferências teóricas e a realidade de sua sala de aula para decidir quais métodos adotará para o ensino-aprendizagem. Nesse sentido, é possível aplicar os métodos tradicionais e os contemporâneos de forma complementar, fazendo uso das distintas abordagens e modelos pedagógicos para aprimorar o ensino-aprendizagem nas modalidades de ensino presencial, híbrido e a distância. No questionário, os participantes responderam sobre os métodos e técnicas utilizados nas aulas e nas avaliações a distância.

Enquanto o ensino presencial se apresenta como a modalidade tradicional de ensino, o ensino a distância trata-se de uma condição mais recente. De acordo com White (2003, p. 14-15), o ensino a distância passou por três fases desde o século passado. Até 1960, essa modalidade ocorria por meio da correspondência por correio, o que não favorecia o ensino de línguas estrangeiras, uma vez que não possibilitava o desenvolvimento das competências orais. A partir da década de 1960, 
começou-se a utilizar audiocassetes, videocassetes, telefone e televisão no ensino a distância. Já a terceira fase é caracterizada pelo uso do computador e da internet.

Quando os computadores começaram a ser utilizados para o ensino, iniciaram-se as pesquisas sobre a Instrução Assistida por Computador (CAI) e Aprendizagem Assistida por Computador (CAL) (Russell, 1982, p. 17). Dentro dessa nova área de investigação, surgiu a Aprendizagem de Línguas Assistida por Computador (CALL), caracterizada por Levy (1997, p. 1) como uma área interdisciplinar por natureza, relacionada à linguística, à pedagogia e à computação.

Diversas investigações foram realizadas acerca da eficácia da CALL. Liu et al. (2002) revisaram a literatura acerca do tema entre os anos 1990 e 2000, enquanto Stockwell (2007) revisou as publicações de 2001 a 2005. Macaro, Handley e Walter (2012) compilaram as investigações sobre o impacto da CALL para o ensino escolar de língua estrangeira de 1990 a 2010. Também há revisões da literatura mais específicas, que analisaram seu impacto exclusivamente no ensino da compreensão escrita (Kim, 2002) ou da produção escrita (Yang, Zhao e Li, 2012) em língua inglesa.

$\mathrm{O}$ ensino a distância é concebido diferentemente, dependendo do nível de desenvolvimento tecnológico de cada época (Levy, 1997, p. 1). Em poucas décadas, a generalização do uso dos computadores e do acesso à internet transformou essa modalidade de ensino radicalmente. Enquanto, anteriormente, era necessário que os estudantes visitassem os laboratórios das instituições para utilizar seus computadores, atualmente já é possível utilizar essa tecnologia em qualquer lugar e momento. A portabilidade tecnológica permite, assim, maior flexibilidade aos estudantes na modalidade do ensino a distância.

O uso da internet na educação a distância permitiu, por exemplo, a criação dos Massive Open Online Courses (MOOCs). Segundo Yuan e Powell (2013, p. 6), o objetivo original dos MOOCs era possibilitar o acesso online gratuito ao ensino superior à maior quantidade de alunos possível, mas na prática muitos MOOCs ou não são gratuitos ou não atingem uma imensa quantidade de alunos. Os autores diferenciam dois tipos de MOOCs, de acordo com o modelo pedagógico adotado: os cMOOCs, que se baseiam na teoria construtivista e utilizam a pedagogia relacional de modo que os estudantes aprendam uns com os outros; e os xMOOCs, criticados por basearem-se na teoria empirista e utilizarem o modelo de "transmissão do conhecimento" da pedagogia diretiva (Yuan e Powell, 2013, p. 11). Este, em especial, parece relacionar-se com a crença que as pessoas em geral têm do ensino a distância. No questionário, será visto o que os respondentes pensam sobre o ensino-aprendizagem nessa modalidade.

A relação entre o ensino a distância e as teorias de ensino-aprendizagem ocorre não somente nos MOOCs, mas na CALL em geral. De acordo com Warschauer (1996), a CALL dividiu-se em três fases de pedagogias distintas: comportamentalista, comunicativa e integrativa. A primeira, influenciada pelo comportamentalismo (Skinner, 1957), prevaleceu até o fim da década de 1970 e caracterizou-se pelos exercícios repetitivos. A segunda durou até o fim da década de 1980 e teve como foco o desenvolvimento da competência comunicativa (Hymes, 1972). Já a terceira fase integrou as competências de compreensão e produção orais e escritas e os recursos multimídia para o uso da língua em contextos autênticos. 
No questionário, foi possível aos participantes responder se de fato identificam como característica do ensino a distância a "inovação nos recursos didáticos" disponibilizados na rede.

Concorda-se com a afirmação de Blake (2008, p. 2), de que a tecnologia apenas oferece ferramentas que são, em geral, metodologicamente neutras. A tecnologia em si não é boa ou ruim para a aprendizagem, mas é o modo como ela é utilizada que pode influenciar a aprendizagem. Isso significa que se pode utilizar o computador simplesmente como meio para disponibilizar os mesmos materiais utilizados no ensino presencial (vídeos, textos, exercícios), sem inovar nos recursos didáticos, ou pode-se utilizá-lo para explorar suas vantagens, como o acesso a ferramentas automáticas de análise de corpora e de criação de questões. Não é a tecnologia que garantirá a inovação nas aulas, mas a atitude do professor em utilizá-la de novas formas.

Heilman et al. (2008), por exemplo, desenvolveram um sistema que busca textos na $W e b$ para serem utilizados no ensino de línguas. A seleção dos textos é realizada com base na escolha de palavras-chave, extensão do documento e dificuldade de leitura, facilitando o trabalho do professor. Outra inovação proporcionada pelo uso do computador no ensino é o que Kapp (2012, p. 9) define como gamification, ou seja, o uso de jogos para motivar os estudantes e promover a aprendizagem. Os jogos utilizados para o ensino são descritos por Michael e Chen (2005, p. 23) como serious games, jogos que, apesar de divertidos e prazerosos, têm como primeiro objetivo algo prático para ensinar algum conteúdo.

Garrison (2011, p. 1) ressalta, acerca do ensino híbrido e a distância, a necessidade de fazer evoluir a experiência de aprendizagem de modo que se possa preparar os estudantes para uma vida profissional ativa e colaborativa, sem cometer o equívoco de tentar integrar as Novas Tecnologias de Informação e Comunicação (NTICs) em abordagens de ensino passivas. Dessa forma, defende-se aqui o uso do computador para o ensino a distância para inovar o ensino por meio do uso ativo de novos recursos, em vez de apenas "transportar" o ensino presencial para o computador. Conforme mencionado, será visto como os respondentes percebem o ensino-aprendizagem e a inovação de recursos no ensino a distância.

Sobre a modalidade de ensino híbrido, Graham (2006) explica que ela pode ser entendida de três formas distintas: como a combinação de diferentes médias; a combinação de métodos; ou a combinação das modalidades presencial e a distância, sendo esta última a sua interpretação. $\mathrm{O}$ ensino híbrido como a combinação das modalidades presencial e a distância também pode ocorrer de distintas formas: pode-se, por exemplo, realizar a parte teórica das aulas a distância e a discussão e atividades presencialmente, ou o inverso.

De acordo com Graham (2006), a modalidade de ensino híbrido combina as modalidades de ensino presencial e a distância na tentativa de unir as vantagens de cada uma. Como vantagens de discussões assíncronas a distância, por exemplo, o autor aponta a maior flexibilidade temporal e geográfica, a participação igualitária e a profundidade de reflexão. Já as desvantagens seriam a menor espontaneidade, dificuldade de conexão humana e tendência à procrastinação. As discussões presenciais, em contrapartida, permitiriam maior espontaneidade e conexão humana como vantagens, mas menor flexibilidade temporal e geográfica e dificuldade de participação igualitária como desvantagens. 
Decidiu-se, neste artigo, propor uma reformulação das possíveis vantagens e desvantagens sugeridas por Graham (2006) acerca das modalidades de ensino, como se vê no Quadro 2. No questionário, os participantes também puderam selecionar as características que relacionam ao ensino a distância. Aqui elas foram agrupadas em três categorias gerais: relação interpessoal, flexibilidade e ensino-aprendizagem. Quando a vantagem está provavelmente presente na modalidade de ensino, ela é marcada no quadro com o sinal de mais (+); quando não está,é marcada com o sinal de menos (-).

Quadro 2 - Comparação das modalidades de ensino.

\begin{tabular}{|c|c|c|c|c|}
\hline \multicolumn{2}{|c|}{ VANTAGENS } & \multicolumn{3}{|c|}{ MODALIDADE DE ENSINO } \\
\hline GERAIS & ESPECÍFICAS & PRESENCIAL & HÍBRIDO & A DISTÂNCIA \\
\hline \multirow{4}{*}{$\begin{array}{l}\text { Relação } \\
\text { interpessoal }\end{array}$} & $\begin{array}{l}\text { Diálogo } \\
\text { espontâneo }\end{array}$ & + & + & - \\
\hline & $\begin{array}{l}\text { Espaço para que } \\
\text { todos participem } \\
\text { igualmente }\end{array}$ & - & + & + \\
\hline & $\begin{array}{l}\text { Estabelecimento } \\
\text { de empatia }\end{array}$ & + & + & - \\
\hline & $\begin{array}{l}\text { Sentimento de } \\
\text { grupo }\end{array}$ & + & + & - \\
\hline \multirow{4}{*}{ Flexibilidade } & Alcance geográfico & - & $+/-$ & + \\
\hline & $\begin{array}{l}\text { Economia de } \\
\text { custos }\end{array}$ & - & $+/-$ & + \\
\hline & $\begin{array}{l}\text { Liberdade de } \\
\text { tempo }\end{array}$ & - & $+/-$ & + \\
\hline & Número de alunos & - & $+/-$ & + \\
\hline \multirow{4}{*}{$\begin{array}{l}\text { Ensino- } \\
\text { aprendizagem }\end{array}$} & $\begin{array}{l}\text { Autonomia dos } \\
\text { alunos }\end{array}$ & - & + & + \\
\hline & $\begin{array}{l}\text { Inovação nos } \\
\text { recursos didáticos }\end{array}$ & - & + & + \\
\hline & $\begin{array}{l}\text { Monitoramento } \\
\text { individual }\end{array}$ & - & + & + \\
\hline & $\begin{array}{l}\text { Necessidade de } \\
\text { organização }\end{array}$ & - & + & + \\
\hline
\end{tabular}

Fonte: Banco de dados da pesquisa. Elaborado pelos autores principalmente com base na leitura de Graham (2006).

Dentro da categoria relação interpessoal, inserem-se o diálogo espontâneo, espaço para que todos participem igualmente, o estabelecimento de empatia ${ }^{9} \mathrm{e} o$ sentimento de grupo ${ }^{10}$. Nas discussões assíncronas a distância, ao contrário do que

9 Para saber mais, ler Holmberg (2013).

10 Para saber mais, ler Rovai e Jordan (2004). 
ocorre em discussões presenciais, todos podem participar igualmente, sem serem silenciados por colegas mais participativos ou em razão de algum preconceito que possam sofrer. Já as outras vantagens (diálogo espontâneo, estabelecimento de empatia e sentimento de grupo) costumam decorrer do contato presencial, existente nas modalidades de ensino presencial e híbrido, e são mais difíceis de obter com a interação assíncrona a distância.

$\mathrm{Na}$ categoria flexibilidade, inserem-se o alcance geográfico, a economia de custos, a liberdade de tempo e o número de alunos. Enquanto esse número é maior no ensino a distância, é um pouco menor no ensino híbrido e consideravelmente menor no ensino presencial.

$\mathrm{Na}$ categoria ensino-aprendizagem, inserem-se a autonomia dos alunos, a inovação nos recursos didáticos, o monitoramento individual e a necessidade de organização. Esses aspectos tendem a ser maiores no ensino híbrido e a distância e menores no ensino presencial. Nessa categoria ainda poderia ser inserido o feedback, que pode ser realizado com o auxílio de expressões faciais no contato presencial e por meio de correções automáticas no ensino a distância.

Nota-se que a modalidade de ensino híbrido tem o objetivo de obter as vantagens do ensino presencial e do ensino a distância, tentando evitar suas desvantagens. Como questão final do questionário, os participantes responderão qual modalidade de ensino pensam que será mais ofertada no futuro: presencial, a distância ou híbrida.

Apesar de algumas pessoas terem uma percepção negativa do ensino a distância, Pellettieri (2000, p. 62) argumenta que os estudantes que participam dessa modalidade seriam mais motivados e confiantes em sua comunicação do que os que têm acesso apenas ao ensino presencial. A motivação e a confiança do estudante estão relacionadas a seu filtro afetivo, uma das hipóteses de Krashen sobre a aquisição de segunda língua.

Krashen (1982) propôs cinco hipóteses sobre a aquisição de segunda língua: a hipótese de aquisição-aprendizagem; a do monitor; a do input; a do filtro afetivo; e a da ordem natural. A primeira diferencia aprendizagem, em que a língua é aprendida formalmente, de aquisição, em que é adquirida naturalmente. A segunda hipótese sugere que cada aprendiz possui um monitor interno que corrige sua produção na língua. A terceira explica que o estudante deve ser exposto sempre a um input compreensível, mas um pouco além de sua competência linguística, para que ele possa avançar. A quarta sugere a existência de um filtro afetivo que, ao estar elevado devido à ansiedade e insegurança, interfere negativamente na aquisição da língua. Por fim, a quinta hipótese é que haja uma ordem natural para a aquisição linguística.

Beauvois (1998) identificou relações existentes entre algumas das hipóteses de Krashen e a Aprendizagem de Línguas Assistida por Computador. A autora aplicou questionários e entrevistou estudantes que tiveram aulas teóricas de francês presencialmente e realizaram sessões de discussões na língua estrangeira através do computador. Os estudantes explicaram que, nas discussões pelo computador, devido à liberdade de tempo para sua participação, conseguiram monitorar melhor a gramática de seus comentários e sentiram-se menos ansiosos do que nas aulas presenciais. Além de identificar a hipótese do monitor e a do filtro afetivo, a autora explicou que, nas discussões por computador, os estudantes tiveram acesso a mais 
input compreensível com seus colegas do que nas aulas teóricas, devido à maior participação e ao fato de eles compartilharem a mesma interlíngua.

Chapelle (2008, p. 30) critica, contudo, que muitas investigações têm comparado o efeito do computador para a aprendizagem como se ele fosse um método de ensino, sem analisar o contexto de aprendizagem proporcionado por cada modalidade e as características individuais dos participantes. Na aplicação do questionário, decidiu-se perguntar aos discentes e docentes do ensino superior sobre sua situação em época de distanciamento social e o que eles pensam do ensino a distância.

Recentemente, foram publicados alguns estudos acerca do ensino a distância durante a pandemia de COVID-19. Na China, alegadamente o país de origem do vírus, o ministro da Educação lançou a iniciativa "Disrupted classes, undisrupted learning" (Huang et al., 2020), também traduzida como "School's out, but class's on" (Zhou et al., 2020). De acordo com Zhou et al. (2020), mais de 270 milhões de estudantes chineses passaram a ter aulas a distância, o que representa o maior evento de educação a distância da história. Os autores defendem que o uso das tecnologias para o ensino em massa, além de contribuir para solucionar a crise atual, contribuirá para a reformulação do ensino.

De modo semelhante aos resultados positivos do ensino a distância reportados no caso chinês, na Universidad Autónoma de Madrid os estudantes demonstraram um avanço nos resultados obtidos com a aprendizagem a distância quando comparados aos resultados de anos anteriores com o ensino presencial (González et al., 2020). Essas transformações nas modalidades de ensino, contudo, implicam determinados desafios, tais como a necessidade de conexão de internet, aparelhos tecnológicos, formação de professores e desenvolvimento de competências digitais e pessoais, tanto para alunos como para professores. No Brasil, as publicações recentes encontradas sobre o tema apontam para a dificuldade de implementação do ensino a distância. Camacho et al. (2020) ressaltam a impossibilidade de cursos e disciplinas práticas serem transferidos para a modalidade de ensino a distância; Oliveira e Souza (2020) destacam a necessidade de formação de professores e de um sistema de avaliação adequado; e, finalmente, Avelino e Mendes (2020, p. 57) explicam que, no contexto atual brasileiro de crise nas áreas de economia, saúde e política, as "questões sociais econômicas e culturais dos alunos também influenciam diretamente nos resultados da aprendizagem". De acordo com os autores,

O Brasil tem enfrentado diversos problemas educacionais ao longo dos anos, apontados principalmente por baixos salários dos educadores, infraestruturas precárias das escolas, diversos tipos de violências, evasão e reprovação, desvios de repasses de verbas, amplo analfabetismo informal e resultados cada vez mais catastróficos nas avaliações internas e externas. (Avelino e Mendes, 2020, p. 56)

Ao considerar algumas variáveis que podem interferir na vida dos estudantes e dos professores do ensino superior, buscou-se compreender o que eles pensam do ensino a distância, mediante a realização de um estudo de caso, com base em questionário aplicado. $\mathrm{Na}$ seção seguinte, serão apresentadas as questões colocadas e analisadas as respostas obtidas. 


\section{PERCEPÇÃO DOS ESTUDANTES E DOS PROFESSORES ACERCA DO ENSINO A DISTÂNCIA}

Um questionário ${ }^{11}$ sobre a percepção de discentes e docentes do ensino superior brasileiro e português acerca do ensino a distância foi divulgado virtualmente durante a última semana de abril de 2020, então compartilhado por meio de listas de e-mails e redes sociais dos autores. Obteve-se a participação de 225 indivíduos, sendo $77 \%$ estudantes ou professores de universidades brasileiras e $23 \%$ de universidades portuguesas. Este estudo baseia-se, pois, numa pequena amostra de conveniência e não pretende ser representativo do universo de estudantes e professores universitários brasileiros e portugueses, embora possa contribuir para a reflexão acerca da temática.

Importante observar que, ainda que o questionário fosse anônimo, metade dos indivíduos disponibilizou seu e-mail para receber a publicação com a análise dos dados recolhidos, o que pode ser interpretado como um sinal de interesse pelo tema.

Entre os respondentes, cerca de $80 \%$ eram do gênero feminino (Questão 1 - Q1 $)^{12}$ e a idade variou de 18 a 70 anos, com mediana de 25 anos (Q2). Aproximadamente $80 \%$ moravam com agregados familiares constituídos por 1 a 4 pessoas (Q3); não moravam com bebês ou crianças (Q4); tinham espaço individual em sua casa para estudar ou trabalhar sem interrupções (Q5); tinham internet funcionando bem (Q8); possuíam e estavam acostumados a utilizar aparelhos tecnológicos (Q9, Q10). Ressalta-se que 96\% dos respondentes estavam cumprindo o distanciamento social (Q16) e 80\% afirmaram que não se sentiam seguros para retornar às aulas presenciais no mês imediato (em maio de 2020) (Q15).

Os participantes dividiam-se entre estudantes da graduação (63\%), estudantes da pós-graduação (24\%) e professores universitários (13\%) (Q34). Todos os professores universitários estavam empregados. A porcentagem de empregados (Q6) entre os estudantes foi de $76 \%$ na pós-graduação e de $54 \%$ na graduação. Em relação à renda (Q7), a maioria dos estudantes da graduação (53\%) e da pós-graduação (59\%) classificou sua situação financeira como "razoável”, enquanto a maioria dos professores universitários (59\%) a classificou como "boa". No Gráfico 1, são apresentados os números de respondentes para cada classificação.

A distribuição percentual dos respondentes nos cursos universitários (Q12) está representada no Gráfico 2. O curso com mais respostas foi o de letras (27\%), seguido de pedagogia (16\%) e psicologia (9\%), havendo uma clara predominância de cursos de humanidades.

Conforme observado na introdução, a forma como as instituições de ensino superior reagiram à situação provocada pela COVID-19 foi diferente entre as univer-

11 Disponível em: https://forms.gle/tA4FrA9PZhVJ115X9. Acesso em: 8 maio 2020.

12 Doravante, as questões serão indicadas pela letra $\mathrm{Q}_{2}$ seguida da respectiva numeração. 


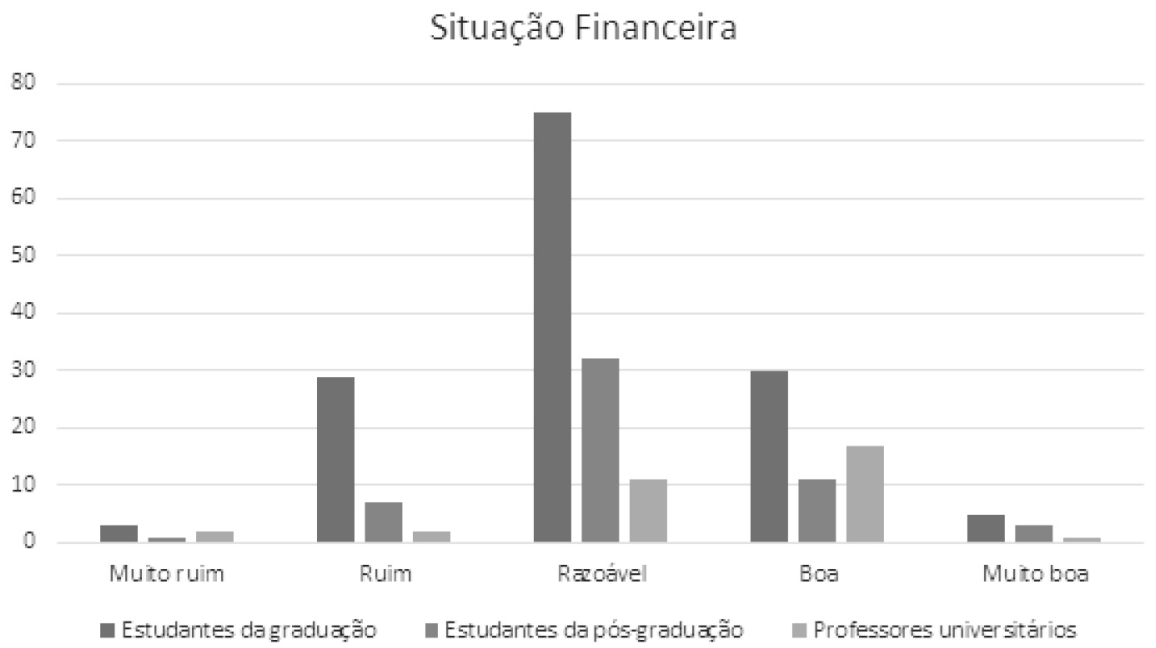

Fonte: Banco de dados da pesquisa.

Gráfico 1 - Classificação da situação financeira

\section{Cursos}

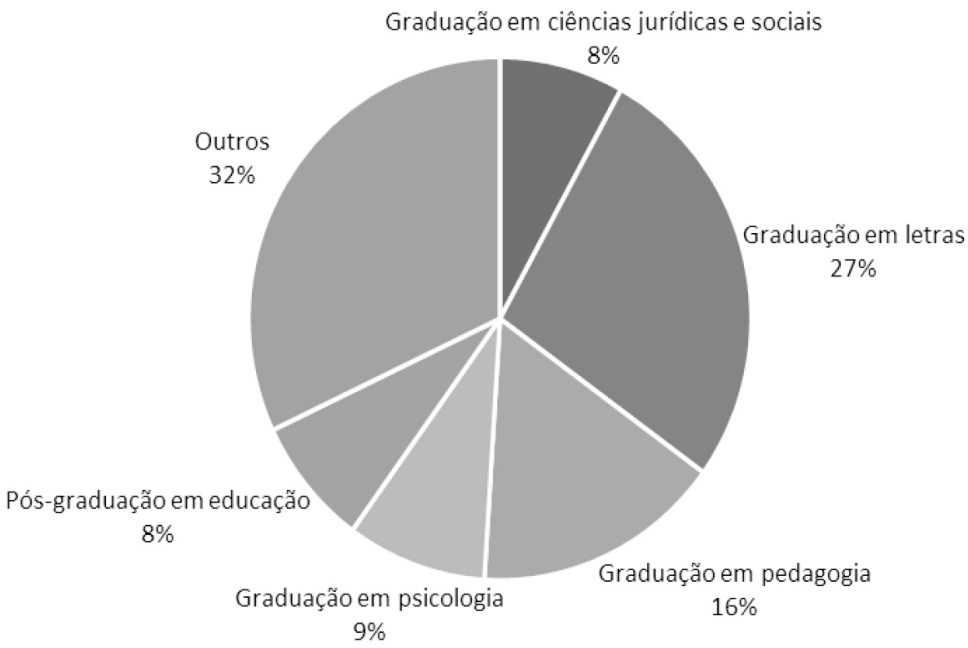

Fonte: Banco de dados da pesquisa.

Gráfico 2-Distribuição de respostas por curso

sidades públicas e privadas, tanto no Brasil quanto em Portugal. A Tabela 1 apresenta a distribuição das respostas por instituição de ensino superior (Q11), identificando se as aulas presenciais foram substituídas por aulas a distância (Q13) e a porcentagem de respondentes de cada instituição que concordavam com a substituição (Q14). 
Tabela 1 - Instituições de ensino.

\begin{tabular}{l|c|c|c}
\hline $\begin{array}{l}\text { Instituição de ensino } \\
\text { superior }\end{array}$ & $\begin{array}{c}\text { Respondentes } \\
(\%)\end{array}$ & $\begin{array}{c}\text { As aulas } \\
\text { estão a } \\
\text { distância? }\end{array}$ & $\begin{array}{c}\text { Quantos } \\
\text { concordam com a } \\
\text { substituição? (\%) }\end{array}$ \\
\hline $\begin{array}{l}\text { Centro Universitário Ritter dos } \\
\text { Reis }\end{array}$ & 12 & Sim & 59 \\
\hline $\begin{array}{l}\text { Pontifícia Universidade Católica } \\
\text { do Rio Grande do Sul }\end{array}$ & 9 & Sim & 40 \\
\hline Universidade do Algarve & 20 & Sim & 83 \\
\hline $\begin{array}{l}\text { Universidade Federal do Rio } \\
\text { Grande do Sul }\end{array}$ & 33 & Não & 66 \\
\hline $\begin{array}{l}\text { Outras universidades brasileiras } \\
\text { com aulas a distância }\end{array}$ & 3 & Não & 25 \\
\hline $\begin{array}{l}\text { Outras universidades brasileiras } \\
\text { com aulas suspensas }\end{array}$ & 3 & Sim & 100 \\
\hline $\begin{array}{l}\text { Outras universidades portuguesas } \\
\text { com aulas a distância }\end{array}$ & 30 & & 40 \\
\hline
\end{tabular}

Fonte: Banco de dados da pesquisa.

Percebe-se que a maioria dos respondentes faziam parte de instituições de ensino superior do estado do Rio Grande do Sul, no Brasil, ou do Algarve, em Portugal. Com exceção da Universidade Federal do Rio Grande do Sul e de outras poucas universidades brasileiras, também públicas e gratuitas (Universidade Federal de Ciências da Saúde de Porto Alegre, Universidade Federal de Santa Catarina e Universidade Estadual do Oeste do Paraná), as outras instituições de ensino superior substituíram as aulas presenciais por aulas a distância.

Enquanto $65 \%$ dos estudantes e professores que tiveram as aulas presenciais substituídas por aulas a distância concordaram com a substituição, apenas 39\% dos que estavam com as aulas suspensas concordaram com essa alternativa. Identifica-se, também, que a concordância com a substituição das aulas presenciais por aulas a distância é maior entre portugueses (78\%) que entre os brasileiros que de fato tiveram suas aulas substituídas (58\%).

Ao considerar os dados dos 144 indivíduos que tiveram suas aulas presenciais substituídas por aulas a distância, constatou-se que todos os respondentes utilizavam a plataforma Moodle ${ }^{13}$ (chamada de Tutoria Eletrónica ${ }^{14} \mathrm{em}$ Portugal) (Q21). Além das plataformas oficiais das instituições de ensino superior, $64 \%$ dos respondentes utilizavam a plataforma $\mathrm{Zoom}^{15} \mathrm{em}$ suas aulas e $24 \%$ utilizavam recursos do Google

13 Disponível em: https://moodle.org/. Acesso em: 8 maio 2020.

14 Disponível em: https://tutoria.ualg.pt/. Acesso em: 8 maio 2020.

15 Disponível em: https://zoom.us/. Acesso em: 8 maio 2020. 
(como Google Classroom ${ }^{16}$ e Google Meet ${ }^{17}$ ). A seguir, serão analisadas apenas as respostas dos 144 indivíduos que tiveram aula a distância (83 estudantes da graduação, 41 estudantes da pós-graduação e 20 professores universitários). Em um primeiro momento, serão analisadas as questões gerais acerca do ensino a distância. $\mathrm{Na}$ sequência serão tratadas as questões mais específicas.

Ao comparar o ensino a distância com o ensino presencial, os respondentes consideraram, em geral, o ensino a distância (Q17) "pior" (71\% dos estudantes da graduação, $78 \%$ dos estudantes da pós-graduação, $60 \%$ dos professores universitários $\left.{ }^{18}\right)$, a comunicação (Q29) também foi considerada "pior" (71\%, 70\%, 60\%), a avaliação (Q30) tida como "mais difícil” (39\%, 46\%, 70\%) e a exigência (Q24) apontada como "maior" (55\%, 44\%, 40\%) que no ensino presencial. Em torno de $65 \%$ dos estudantes, tanto de graduação como de pós-graduação, consideraram a aprendizagem (Q22) nas aulas a distância "pior" que nas aulas presenciais. Os professores, no entanto, dividiram-se em três respostas: um terço considerou a aprendizagem "igual", um terço indicou "não sabe", e um terço a considerou "pior".

Acerca do tempo dedicado (Q25) ao ensino a distância, 60\% dos professores o consideraram "maior" que o tempo dedicado ao ensino presencial. Já os estudantes dividiram-se em suas respostas: na graduação, 36\% o consideraram "menor"; $35 \%$ "maior"; $27 \%$ "igual", e o restante "não sabe"; na pós-graduação, 39\% o consideraram "menor"; 29\% "maior"; 29\% "igual”, e o restante "não sabe". Os participantes distinguiram-se em sua dedicação (Q23): 45\% dos estudantes de graduação dedicaram-se "menos" às aulas a distância que às aulas presenciais, enquanto $37 \%$ dos estudantes de pós-graduação dedicaram-se "igualmente", e 55\% dos professores dedicaram-se "mais".

A distribuição das respostas para cada questão está organizada na Tabela 2.

Quando questionados sobre o modelo pedagógico (Q19) (diretivo, não diretivo ou relacional) utilizado em suas aulas no ensino superior, a maioria dos respondentes afirmou haver uma "combinação" dos distintos modelos (46\%, 41\%, $55 \%)$, seguida pelo modelo relacional, em que "professor e alunos aprendem juntos" $(28 \%, 41 \%, 40 \%)$. Considerando os possíveis tipos de aula a distância (Q18) (com vídeo ao vivo, com vídeo gravado, sem vídeo), a maioria preferia ter aula virtual "síncrona" (49\%, 66\%, 80\%). Em relação aos tipos de avaliação (Q31), as opções mais selecionadas foram "prova de múltipla escolha" (46\%, 27\%, 25\%) e "trabalho individual" (31\%, 44\%, 35\%).

Os participantes foram questionados se conseguiam resolver suas dúvidas a distância (Q28), e as respostas mais obtidas foram "às vezes" (59\%, 29\%, 20\%) ou "sim" (33\%, 29\%, 80\%). A maioria considerou os professores "razoavelmente" $(53 \%, 34 \%, 30 \%)$ ou "bastante" $(28 \%, 39 \%, 30 \%)$ adaptados às tecnologias (Q20).

16 Disponível em: https://classroom.google.com/. Acesso em: 8 maio 2020.

17 Disponível em: https://meet.google.com/. Acesso em: 8 maio 2020.

18 Para evitar a repetição desnecessária, a apresentação das porcentagens dentro dos parênteses seguirá a mesma ordem: primeiro estudantes da graduação, depois estudantes da pós-graduação e, por fim, professores universitários. 
Tabela 2 - Análise da primeira parte dos dados.

\begin{tabular}{|c|c|c|c|c|}
\hline & & $\begin{array}{l}\text { Estudantes } \\
\text { da } \\
\text { graduação } \\
\text { (N=83) }\end{array}$ & $\begin{array}{l}\text { Estudantes } \\
\text { da pós- } \\
\text { graduação } \\
\text { (N=41) }\end{array}$ & $\begin{array}{l}\text { Professores } \\
\text { universitários } \\
\qquad(\mathrm{N}=20)\end{array}$ \\
\hline \multirow{4}{*}{$\begin{array}{l}\text { 17. Como você } \\
\text { considera o ensino } \\
\text { a distância? }\end{array}$} & $\begin{array}{l}\begin{array}{l}\text { Melhor que o } \\
\text { presencial }\end{array} \\
\end{array}$ & 2 & 1 & 2 \\
\hline & Igual ao presencial & 17 & 4 & 5 \\
\hline & Pior que o presencial & 59 & 32 & 12 \\
\hline & Não sei & 5 & 4 & 1 \\
\hline \multirow{4}{*}{$\begin{array}{l}\text { 29. Você acredita } \\
\text { que a comunicação } \\
\text { entre os } \\
\text { participantes seja } \\
\text { afetada pelo ensino } \\
\text { a distância? }\end{array}$} & Sim, para melhor & 8 & 2 & 3 \\
\hline & Sim, para pior & 59 & 29 & 12 \\
\hline & Não & 8 & 7 & 3 \\
\hline & Não sei & 8 & 3 & 2 \\
\hline \multirow{4}{*}{$\begin{array}{l}\text { 30. Como } \\
\text { você considera } \\
\text { a avaliação a } \\
\text { distância? }\end{array}$} & $\begin{array}{l}\text { Mais fácil que a } \\
\text { presencial }\end{array}$ & 23 & 8 & 2 \\
\hline & Igual à presencial & 14 & 8 & 2 \\
\hline & $\begin{array}{l}\text { Mais difícil que a } \\
\text { presencial }\end{array}$ & 32 & 19 & 14 \\
\hline & Não sei & 14 & 6 & 2 \\
\hline \multirow{4}{*}{$\begin{array}{l}\text { 24. Como é o grau } \\
\text { de exigência das } \\
\text { aulas a distância? }\end{array}$} & $\begin{array}{l}\text { Maior que nas aulas } \\
\text { presenciais }\end{array}$ & 46 & 18 & 8 \\
\hline & $\begin{array}{l}\text { Igual ao das aulas } \\
\text { presenciais }\end{array}$ & 15 & 12 & 7 \\
\hline & $\begin{array}{l}\text { Menor que nas aulas } \\
\text { presenciais }\end{array}$ & 20 & 10 & 3 \\
\hline & Não sei & 2 & 1 & 2 \\
\hline \multirow{4}{*}{$\begin{array}{l}\text { 22. Como é a } \\
\text { aprendizagem nas } \\
\text { aulas a distância? }\end{array}$} & $\begin{array}{l}\text { Melhor que nas aulas } \\
\text { presenciais }\end{array}$ & 5 & 2 & 2 \\
\hline & $\begin{array}{l}\text { Igual à nas aulas } \\
\text { presenciais }\end{array}$ & 16 & 10 & 7 \\
\hline & $\begin{array}{l}\text { Pior que nas aulas } \\
\text { presenciais }\end{array}$ & 54 & 26 & 5 \\
\hline & Não sei & 8 & 3 & 6 \\
\hline \multirow{4}{*}{$\begin{array}{l}\text { 25. Como é o } \\
\text { tempo dedicado às } \\
\text { aulas a distância? }\end{array}$} & $\begin{array}{l}\text { Maior que nas aulas } \\
\text { presenciais }\end{array}$ & 29 & 12 & 12 \\
\hline & $\begin{array}{l}\text { Igual ao das aulas } \\
\text { presenciais }\end{array}$ & 22 & 12 & 6 \\
\hline & $\begin{array}{l}\text { Menor que nas aulas } \\
\text { presenciais }\end{array}$ & 30 & 16 & 2 \\
\hline & Não sei & 2 & 1 & 0 \\
\hline
\end{tabular}


Tabela 2 - Continuação.

\begin{tabular}{|c|c|c|c|c|}
\hline & & $\begin{array}{l}\text { Estudantes } \\
\text { da } \\
\text { graduação } \\
\text { (N=83) }\end{array}$ & $\begin{array}{l}\text { Estudantes } \\
\text { da pós- } \\
\text { graduação } \\
(\mathrm{N}=41)\end{array}$ & $\begin{array}{l}\text { Professores } \\
\text { universitários } \\
\text { (N = 20) }\end{array}$ \\
\hline \multirow{4}{*}{$\begin{array}{l}\text { 23. Como é sua } \\
\text { dedicação nas aulas } \\
\text { a distância? }\end{array}$} & $\begin{array}{l}\text { Maior que nas aulas } \\
\text { presenciais }\end{array}$ & 21 & 12 & 11 \\
\hline & $\begin{array}{l}\text { Igual à nas aulas } \\
\text { presenciais }\end{array}$ & 24 & 15 & 7 \\
\hline & $\begin{array}{l}\text { Menor que nas aulas } \\
\text { presenciais }\end{array}$ & 37 & 14 & 1 \\
\hline & Não sei & 1 & 0 & 1 \\
\hline
\end{tabular}

Fonte: Banco de dados da pesquisa.

Em relação à carga de estudos, a maioria declarou sentir-se sobrecarregada (Q27) no ensino a distância $(67 \%, 59 \%, 70 \%)$. Também se perguntou aos indivíduos se eles se sentiam bem física e mentalmente para o ensino a distância (Q26), ao que 55\% dos professores universitários e $46 \%$ dos estudantes da pós-graduação responderam "sim", enquanto 54\% dos estudantes da graduação responderam "não". Além dessas duas alternativas, podiam responder "não sei".

$\mathrm{Na}$ Tabela 3 está organizada a distribuição das respostas para cada questão.

Os respondentes, por fim, selecionaram as características que associavam ao ensino a distância (Q32). Visto que essa questão difere das outras pela possibilidade de seleção de múltiplas respostas, decidiu-se pela não divisão dos participantes entre estudantes e professores. Os resultados estão organizados no Gráfico 3.

Ao comparar o Gráfico 3 com o quadro proposto na revisão da literatura (Quadro 2), percebe-se que são semelhantes. As principais diferenças são as características "espaço para que todos participem igualmente", "maior número de alunos" e "monitoramento individual dos estudantes pelos professores", que haviam sido relacionadas ao ensino a distância na proposta inicial, mas foram pouco selecionadas pelos respondentes. Ainda assim, e ao contrário do esperado, apenas a característica "monitoramento individual dos estudantes pelos professores" obteve de fato um número bastante baixo de respostas. Esse resultado pode ter ocorrido em virtude do pouco tempo de organização que as instituições de ensino superior tiveram para substituir suas aulas presenciais por aulas a distância. Considerando essa limitação temporal, é compreensível que as universidades não tenham conseguido contratar tutores nem preparar professores para o monitoramento do progresso individual dos alunos, função considerada essencial ao ensino a distância (Camacho et al., 2020).

Em relação ao futuro das diferentes modalidades no ensino superior (Q33), 65\% de todos os respondentes afirmaram acreditar que será mais ofertada a modalidade híbrida (parte presencial e parte a distância). Alguns respondentes registraram ao fim do questionário (em um espaço dedicado a comentários suplementares) observações favoráveis ao ensino a distância, afirmando que "O ensino 
Tabela 3 - Análise da segunda parte dos dados.

\begin{tabular}{|c|c|c|c|c|}
\hline & & $\begin{array}{l}\text { Estudantes } \\
\text { da } \\
\text { graduação } \\
\text { (N=83) }\end{array}$ & $\begin{array}{l}\text { Estudantes } \\
\text { da pós- } \\
\text { graduação } \\
(\mathrm{N}=41)\end{array}$ & $\begin{array}{l}\text { Professores } \\
\text { universitários } \\
\text { (N=20) }\end{array}$ \\
\hline \multirow{5}{*}{$\begin{array}{l}\text { 19. Como você } \\
\text { descreveria suas } \\
\text { aulas no ensino } \\
\text { superior? }\end{array}$} & $\begin{array}{l}\text { O professor e os alunos } \\
\text { aprendem juntos }\end{array}$ & 23 & 17 & 8 \\
\hline & $\begin{array}{l}\text { O professor ensina e os } \\
\text { alunos aprendem }\end{array}$ & 16 & 5 & 0 \\
\hline & $\begin{array}{l}\text { O professor não interfere } \\
\text { e os alunos aprendem } \\
\text { sozinhos ou entre si }\end{array}$ & 3 & 1 & 1 \\
\hline & $\begin{array}{l}\text { Uma combinação das } \\
\text { opções anteriores }\end{array}$ & 38 & 17 & 11 \\
\hline & $\begin{array}{l}\text { Nenhuma das opções } \\
\text { anteriores }\end{array}$ & 3 & 1 & 0 \\
\hline \multirow{5}{*}{$\begin{array}{l}\text { 18. Você prefere } \\
\text { qual tipo de aula } \\
\text { a distância? }\end{array}$} & $\begin{array}{l}\text { Síncrona (professor em } \\
\text { vídeo ao vivo) }\end{array}$ & 41 & 27 & 16 \\
\hline & $\begin{array}{l}\text { Assíncrona (professor em } \\
\text { vídeo gravado) }\end{array}$ & 15 & 6 & 2 \\
\hline & $\begin{array}{l}\text { Sem vídeos, apenas } \\
\text { atividades }\end{array}$ & 4 & 2 & 0 \\
\hline & Não sei & 2 & 1 & 1 \\
\hline & $\begin{array}{l}\text { Não gosto de aula a } \\
\text { distância }\end{array}$ & 21 & 5 & 1 \\
\hline \multirow{5}{*}{$\begin{array}{l}\text { 31. Você prefere } \\
\text { qual tipo de } \\
\text { avaliação a } \\
\text { distância? }\end{array}$} & $\begin{array}{l}\text { Prova com questões de } \\
\text { múltipla escolha }\end{array}$ & 38 & 11 & 5 \\
\hline & $\begin{array}{l}\text { Prova com questões } \\
\text { dissertativas }\end{array}$ & 10 & 9 & 3 \\
\hline & Trabalho em grupo & 8 & 3 & 1 \\
\hline & \begin{tabular}{|l|} 
Trabalho individual \\
\end{tabular} & 26 & 18 & 7 \\
\hline & Outras opções & 1 & 0 & 4 \\
\hline \multirow{3}{*}{$\begin{array}{l}\text { 28. Você } \\
\text { consegue resolver } \\
\text { suas dúvidas com } \\
\text { outros alunos } \\
\text { e professores a } \\
\text { distância? }\end{array}$} & Sim & 27 & 12 & 16 \\
\hline & Às vezes & 49 & 23 & 4 \\
\hline & Não & 7 & 6 & 0 \\
\hline \multirow{5}{*}{$\begin{array}{l}\text { 20. Quanto } \\
\text { os professores } \\
\text { parecem } \\
\text { adaptados às } \\
\text { tecnologias? }\end{array}$} & Nem um pouco & 0 & 2 & 2 \\
\hline & Pouco & 9 & 5 & 3 \\
\hline & Razoavelmente & 43 & 14 & 6 \\
\hline & Bastante & 23 & 16 & 6 \\
\hline & Totalmente & 8 & 4 & 3 \\
\hline
\end{tabular}


Tabela 3 - Continuação.

\begin{tabular}{l|c|c|c|c}
\hline & & $\begin{array}{c}\text { Estudantes } \\
\text { da } \\
\text { graduação } \\
(\mathrm{N}=83)\end{array}$ & $\begin{array}{c}\text { Estudantes } \\
\text { da pós- } \\
\text { graduação } \\
(\mathrm{N}=41)\end{array}$ & $\begin{array}{c}\text { Professores } \\
\text { universitários } \\
\text { (N = 20) }\end{array}$ \\
\hline $\begin{array}{l}\text { 27. Você se sente } \\
\text { sobrecarregado } \\
\text { no ensino a } \\
\text { distância? }\end{array}$ & Sim & 56 & 24 & 14 \\
\cline { 2 - 5 } \begin{tabular}{l} 
26. Você se sente \\
bem (física e \\
mentalmente) \\
\cline { 2 - 5 } $\begin{array}{l}\text { para o ensino a } \\
\text { distância? }\end{array}$
\end{tabular} & Não & 19 & 15 & 5 \\
\cline { 2 - 5 } & Nimo sei & 8 & 2 & 1 \\
\hline
\end{tabular}

Fonte: Banco de dados da pesquisa.

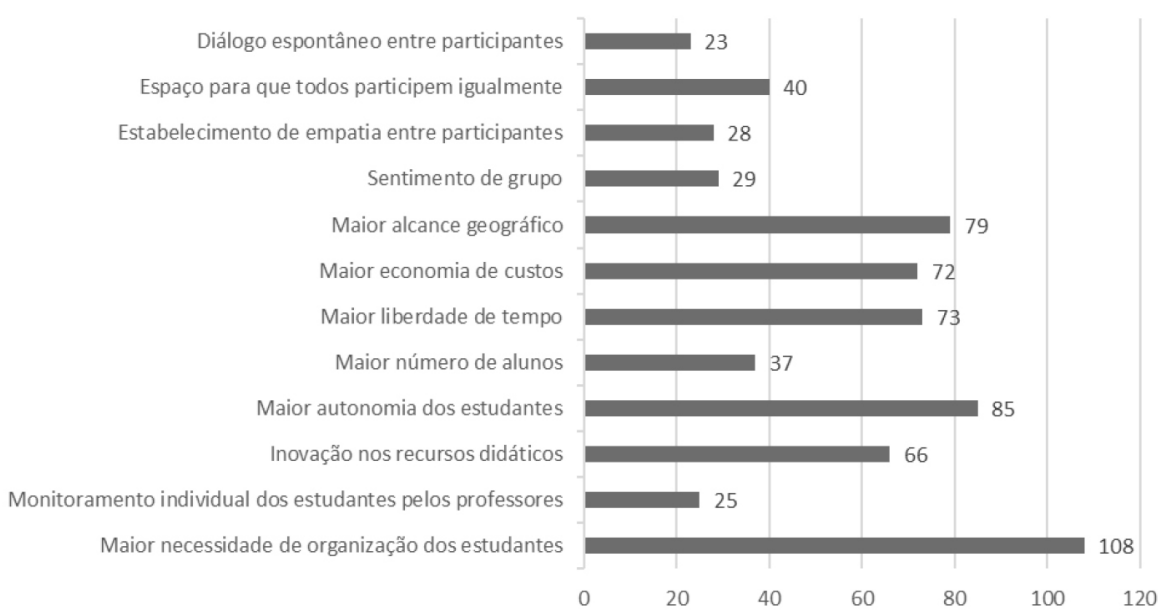

Fonte: Banco de dados da pesquisa.

Gráfico 3 - Características associadas ao ensino a distância.

a distância faz o aluno ser o protagonista; e o professor, o facilitador. Proporciona maior autonomia do estudante, tornando-o mais crítico. É o futuro", demonstrando até mesmo uma mudança positiva em sua percepção: "Não gostava até conhecer a plataforma e a universidade em que estou, muito dinâmica, com aulas síncronas e bastante relacionamento. Para mim mudou meu conceito". Contudo, apesar dos comentários positivos, como os mencionados, outros trouxeram preocupações:

Acredito que ainda tenha muito a melhorar, os professores continuam com o mesmo ritmo de aulas presenciais, porém as dificuldades são maiores, inclusive de concentração, as aulas ficaram mais densas e pesadas, o processo de adaptação está sendo imposto 
e forçado, o valor da mensalidade continua o mesmo, com o argumento de que o que estamos tendo não é o ensino a distância, a universidade está preocupada apenas com o fator financeiro e pouco com o conhecimento absorvido.

Outro respondente declarou:

Acredito que a maioria dos professores não esteja adaptado a este tipo de didática. Não envolve só saber utilizar os recursos, mas as aulas devem ser preparadas de forma diferenciada. O sentimento é que, como as aulas estão sendo online, bá uma sobrecarga de atividades, tarefas e textos que nas aulas presenciais não existiam. Há necessidade de desenvolver uma prática e uma didática mais eficaz.

Apesar de alguns estudantes considerarem como vantagens do ensino a distância o desenvolvimento de maior autonomia dos alunos e as dinâmicas proporcionadas pelas aulas síncronas, outros disseram sentir-se sobrecarregados e com dificuldades de adaptação à modalidade de ensino em que passaram a ter aulas. Criticaram, também, a possível preocupação de algumas universidades com a situação financeira da instituição, mas não com a efetiva aprendizagem dos estudantes.

Conforme um dos respondentes escreveu, "O ensino a distância feito sem a devida preparação pode constituir uma fraude científica e pedagógica”. De acordo com os respondentes, quando as aulas presenciais foram suspensas, não houve muito tempo para as universidades, professores e alunos se prepararem para a substituição por aulas a distância. Por essa razão, como visto na análise do questionário, alguns poderão ter considerado o ensino a distância pior que o ensino presencial. Porém, se os professores receberem formação para ensinar nessa modalidade e os estudantes tiverem acesso aos meios tecnológicos necessários e à internet, o ensino a distância talvez seja capaz de atingir os mesmos resultados do ensino presencial. Até lá, as apostas para o futuro parecem apontar para a adoção da modalidade de ensino híbrido, de modo que possa unir as vantagens tanto do ensino a distância como do ensino presencial.

\section{CONSIDERAÇÕES FINAIS}

Este artigo apresentou uma breve revisão sobre as modalidades de ensino presencial, híbrida e a distância, bem como os resultados de um questionário divulgado virtualmente durante a última semana de abril de 2020. Ao todo, 225 estudantes e professores do ensino superior do Brasil e de Portugal responderam ao questionário. Contudo, apenas 144 tiveram suas aulas presenciais substituídas por aulas a distância. Os dados desses 144 indivíduos foram analisados no artigo.

A maioria dos respondentes afirmou ter condições para estudar a distância: possuíam um espaço individual para estudo, internet e meios tecnológicos em suas casas; além disso, a maioria não convivia com bebês ou crianças e apresentava uma situação econômica razoável. Ressalta-se que, em relação aos estudantes, a preocupação financeira era maior que em relação aos professores, que classificaram sua situação econômica como "boa". Sabemos, no entanto, que essa situação não é 
geral nem uniforme na comunidade acadêmica do Brasil e de Portugal, havendo professores e estudantes que não têm as condições essenciais para acesso ao ensino a distância.

As universidades portuguesas - que, mesmo públicas, são pagas - e as universidades privadas brasileiras substituíram as aulas presenciais por aulas a distância desde o início do distanciamento social imposto pelo agravamento dos casos de COVID-19. De outro modo, as universidades públicas brasileiras optaram por suspender suas aulas. Viu-se que aqueles que tinham aulas a distância concordaram com a substituição, especialmente em Portugal, enquanto aqueles que estavam sem aulas em geral não concordaram com sua substituição, possivelmente em virtude de diferenças culturais, sociais e econômicas dos dois países.

A maioria dos respondentes considerou o ensino a distância pior que o ensino presencial, também considerou a comunicação pior, a avaliação mais difícil, a exigência maior e a aprendizagem pior. Além disso, os dados revelam que os professores julgam empregar muito mais de seu tempo e dedicação para o ensino a distância, enquanto os alunos parecem dedicar-se menos. Em geral, os participantes consideraram que os professores se adaptaram relativamente bem ao uso das novas tecnologias nessa modalidade.

Em relação aos tipos de aulas e avaliações a distância, percebeu-se uma preferência pelas aulas síncronas por vídeo e pela avaliação por trabalhos individuais. Os estudantes da graduação, contudo, indicaram preferir a avaliação por provas de múltipla escolha. A maioria dos professores e estudantes de pós-graduação sentia-se física e mentalmente bem para participar no ensino a distância; já os estudantes de graduação afirmaram o contrário.

Ao serem questionados sobre o futuro das diferentes modalidades no ensino superior, a maioria dos respondentes declarou acreditar que a mais utilizada será a modalidade híbrida. Apesar de o ensino a distância proporcionar diversas vantagens, os participantes afirmaram sentir falta da interação face a face.

O debate entre o ensino a distância, o ensino híbrido e o ensino presencial parece ser importante para o futuro da educação, uma vez que se faz necessário repensar tanto o modo de ensinar como o modo de aprender. Como se viu na revisão da literatura, não basta utilizar a tecnologia para transpor o ensino presencial para o ensino a distância, mas fazer uso de novos recursos didáticos para inovar o processo de ensino-aprendizagem. O professor torna-se um mediador, e o aluno ganha mais liberdade de tempo, espaço e recursos para aprender. Enquanto os encontros presenciais podem ser dedicados a discussões, pode-se utilizar as plataformas digitais para disponibilização de materiais e para criação de espaços colaborativos em que todos possam compartilhar suas descobertas e esclarecer suas dúvidas em conjunto.

Apesar da importância da reflexão sobre as distintas modalidades de ensino, em tempos emergenciais como o atual, em que a modalidade a distância é a única opção, é urgente pensar em como garantir que todos tenham acesso de qualidade a ela. Simplesmente suspender as aulas não parece viável, considerando que seja possível demorar muito tempo até que a situação retorne ao normal. Ainda assim, a mera transposição do ensino presencial para o ensino a distância tampouco é garantia de acesso igualitário e de efetiva aprendizagem. Como possíveis soluções, 
as instituições, devidamente apoiadas, poderiam realizar empréstimos de equipamentos tecnológicos e oferecer serviço de internet gratuito aos estudantes que deles precisem. Além disso, é urgente realizar diferentes ações de formação, quer para professores, quer para alunos, sobre essas novas formas de ensinar e aprender. O debate precisa ser construído com cada comunidade, de modo que identifique as demandas dos envolvidos e se possa pensar coletivamente em estratégias para atendê-las.

\section{AGRADECIMENTOS}

Agradecemos a todas as pessoas que contribuíram para este estudo ao responder ou divulgar o questionário, bem como às instituições que divulgaram a pesquisa.

\section{REFERÊNCIAS}

ANTHONY, E. Approach, method and technique. English Language Teaching, v. 17, n. 2, p. 63-67, 1963. https://doi.org/10.1093/elt/XVII.2.63

AVELINO, W. F.; MENDES, J. G. A realidade da educação brasileira a partir da COVID-19. Boletim de Conjuntura, v. 2, n. 5, p. 56-62, 2020. http://dx.doi. org/10.5281/zenodo.3759679

BEAUVOIS, M. E-Talk: Computer-assisted classroom discussion-attitudes and motivation. In: SWAFFAR, J. et al. Language learning online: Theory and practice in the ESL and L2 Computer Classroom. Austin: Labyrinth Publications, 1998. p. 99-120. BECKER, F. Modelos pedagógicos e modelos epistemológicos. Educação e Realidade, v. 19, n. 1, p. 89-96, 1994.

BLAKE, R. Brave new digital classroom: technology and foreign language learning. Washington: Georgetown University Press, 2008.

BLOOMFIELD, L. Outline guide for the practical study of foreign languages. Baltimore: Linguistic Society of America, 1942.

BROWN, H. Principles of language learning and teaching. Nova York: Longman, 2007.

BRUSCATO, A. M.; BAPTISTA, J. Relações entre teorias linguísticas, teorias da aprendizagem e métodos de ensino de línguas. Educação, Cultura e Sociedade, v. 10, n. 2, p. 324-338, 2020.

CAMACHO, A. C. L. F. et al. A tutoria na educação à distância em tempos de COVID-19: orientações relevantes. Research, Society and Development, v. 9, n. 5, p. e30953151, 2020. https://doi.org/10.33448/rsd-v9i5.3151

CHAPELLE, C. Computer Assisted Language Learning. In: SPOLSKY, B.; HULT, F. (org.). Handbook of Educational Linguistics. Malden: Blackwell, 2008. p. 585-595. CUNHA, A.; BRUSCATO, A. M. A contribution to ESP Teachers'Training. Annals of Dimitrie Cantemir Christian University: Linguistics, Literature and Methodology of Teaching, v. 18, n. 2, p. 89-107, 2019. 
GARRISON, D. E-learning in the 21st century: A framework for research and practice. Nova York: Routledge, 2011.

GONZÁLEZ, T. et al. Influence of COVID-19 confinement in students' performance in higher education. arXiv preprint, arXiv:2004.09545, 2020.

GRAHAM, C. Blended Learning Systems: Definition, Current Trends, and Future Directions. In: BONK, C.; GRAHAM, C. (org.). The Handbook of Blended Learning: Global Perspectives, Local Designs. San Francisco: John Wiley \& Sons, 2006. p. 3-21.

HEILMAN, M. et al. Retrieval of reading materials for vocabulary and reading practice. In: WORKSHOP ON INNOVATIVE USE OF NLP FOR BUILDING EDUCATIONAL APPLICATIONS, 3., 2008. Anais [...]. 2008. p. 80-88.

HOLMBERG, B. A theory of distance education based on empathy. In: MOORE, M.; ANDERSON, W. (org.). Handbook of Distance Education. Mahwah: Lawrence Erlbaum Associates, 2013. p. 79-86.

HUANG, R. H. et al. Handbook on Facilitating Flexible Learning During Educational Disruption: The Chinese Experience in Maintaining Undisrupted Learning in COVID-19 Outbreak. Beijing: Smart Learning Institute of Beijing Normal University, 2020.

HYMES, D. On Communicative Competence. In: PRIDE, J. B.; HOLMES, J. (org.). Sociolinguistics. Selected Readings. Harmondsworth: Penguin, 1972. p. 269-293.

KAPP, K. M. The gamification of learning and instruction: Game-based methods and strategies for training and education. San Francisco: Wiley, 2012.

KIM, M. The Use of the Computer in Developing L2 Reading Comprehension: Literature Review and Its Implications. ERIC Document Reproduction Service No. 472 671. 2002. 30 p.

KRASHEN, S. Principles and practice in second language acquisition. Nova York: Pergamon, 1982.

LEVY, M. Computer-Assisted Language Learning: Context and Conceptualization. Oxford: Oxford University Press, 1997.

LIU, M. et al. A Look at the Research on Computer-Based Technology Use in Second Language Learning: A Review of the Literature from 1990-2000. Journal of Research on Technology in Education, v. 34, n. 3, p. 250-273, 2002. https://doi.org/10.1080/1 5391523.2002.10782348

MACARO, E.; HANDLEY, Z.; WALTER, C. A Systematic Review of CALL in English as a Second Language: Focus on Primary and Secondary Education. Language Teaching, v. 45, n. 1, p. 1-43, 2012. https://doi.org/10.1017/S0261444811000395

MICHAEL, D.; CHEN, S. Serious games: Games that educate, train, and inform. Boston: Thomson Course Technology, 2005.

OLIVEIRA, H.; SOUZA, F. Do conteúdo programático ao sistema de avaliação: reflexões educacionais em tempos de pandemia (COVID-19). Boletim de Conjuntura, v. 2, n. 5, p. 15-24, 2020. http://dx.doi.org/10.5281/zenodo.3753654 
PELLETTIERI, J. Negotiation in cyberspace: The role of chatting in the development of grammatical competence. In: WARSCHAUER, M.; KERN, R. (org.). Networkbased language teaching: Concepts and practice. Cambridge: Cambridge University Press, 2020. p. 59-86.

PRABHU, N. There is no best method - why? Tesol Quarterly, v. 24, n. 2, p. 161-176, 1990. https://doi.org/10.2307/3586897

ROVAI, A.; JORDAN, H. Blended learning and sense of community: A comparative analysis with traditional and fully online graduate courses. The International Review of Research in Open and Distributed Learning, v. 5, n. 2, p. 1-13, 2004. https://doi. org/10.19173/irrodl.v5i2.192

RUSSELL, J. Computers and Foreign Language Instruction. Journal of Language Learning Technologies, v. 16, n. 3-4, p. 17-24, 1982.

SKINNER, B. Verbal Behavior. Nova York: Appleton-Century-Crofts, 1957.

STOCKWELL, G. A Review of Technology Choice for Teaching Language Skills and Areas in the CALL Literature. ReCALL, v. 19, n. 2, p. 105-120,2007. https://doi. org/10.1017/S0958344007000225

TEIXEIRA, P. Internacionalização e Ensino Superior em Portugal: Tendências, Processos e Desafios. In: CONSELHO NACIONAL DE EDUCAÇÃO. Lei de bases do sistema educativo: Balanço e Prospetiva. Lisboa: Conselho Nacional de Educação, 2017.v. 2. p. 705-727.

TERRELL, T. A Natural Approach to Second Language Acquisition and Learning. The Modern Language Journal, v. 61, n. 7, p. 325-337, 1977. https:// doi.org/10.2307/324551

WARSCHAUER, M. Computer-Assisted Language Learning: An Introduction. In: FOTOS, S. (org.). Multimedia Language Teaching. Tóquio: Logos International, 1996. p. 3-20.

WHITE, C. Language Learning in Distance Education. Cambridge: Cambridge University Press, 2003.

WILKINS, D. A Communicative Approach to Syllabus Construction in Adult Language Learning. In: A UNIT/CREDIT SYSTEM FOR MODERN LANGUAGES IN ADULT EDUCATION SYMPOSIUM, St. Wolfgang, 1973. Anais [...]. 1973.p. 1-8.

YANG, L.; ZHAO, L.; LI, Y. Review on Study of Computer-Assisted and NetAssisted EFL Writing during Recent Ten Years. Journal of Educational Institute of Jilin Province, n. 2, p. 84-86, 2012.

YUAN, L.; POWELL, S. MOOCs and open education: Implications for higher education. Bolton: Centre for Educational Technology and Interoperability Standards, 2013.

ZHOU, L. et al. "School's Out, But Class' On”, The Largest Online Education in the World Today: Taking China's Practical Exploration During The COVID-19 Epidemic Prevention and Control As an Example. Best Evid Chin Edu, v. 4, n. 2, p. 501-519, 2020. https://dx.doi.org/10.2139/ssrn.3555520 


\section{SOBRE OS AUTORES}

Amanda Maraschin Bruscato é doutoranda em ciências da linguagem pela Universidade do Algarve (Portugal).

E-mail: amandabruscato@gmail.com

Jorge BAPtista é doutor em ciências da linguagem pela Universidade do Algarve (Portugal). Professor da mesma instituição e do Instituto de Engenharia de Sistemas e Computadores: Investigação e Desenvolvimento em Lisboa INESC-ID Lisboa/HLT (Portugal).

E-mail: jbaptis@ualg.pt

Conflitos de interesse: Os autores declaram que não possuem nenhum interesse comercial ou associativo que represente conflito de interesses em relação ao manuscrito.

Financiamento: Fundação para a Ciência e a Tecnologia (referência UIDB/50021/2020).

Contribuições dos autores: Administração do Projeto, Análise Formal, Conceituação, Curadoria de Dados, Escrita - Primeira Redação: Bruscato, A. M. Escrita - Revisão e Edição: Bruscato, A. M.; Baptista, J. Supervisão: Baptista, J.

Recebido em 8 de maio de 2020 Aprovado em 4 de setembro de 2020 